\title{
O COMPLEXO DE USINAS DO RIO MADEIRA E O DESENVOLVIMENTO SUSTENTÁ VEL: UMA ANÁLISE DOS IMPACTOS DAS OBRAS NAS RELAÇÕES DE TRABALHO
}

\section{Walter Gustavo da Silva Lemos ${ }^{1}$}

RESUMO: O presente artigo científico busca promover uma análise do conceito de desenvolvimento sustentável e das normas internacionais correlatas, na promoção da sua compreensão como trabalho digno e decente, com o objetivo de expor os fatos decorrentes da implementação das obras do Complexo de usinas do rio Madeira, para verificar se as relações de trabalho resultantes destes projetos foram devidamente aplicados em sua implementação. Dessa forma, busca-se investigar os impactos vivenciados nas relações laborais e os descumprimentos das normas existentes para a regência destas concepções. Tal estudo se dá por via do método de abordagem dedutivo, usando do procedimento comparativo, monográfico e bibliográfico, para conectar tais ideias e demonstrar que as obras realizadas não buscaram o desenvolvimento de um ambiente social sustentável ao não implementar condições dignas e decentes de trabalho.

Palavras-Chave: Usinas do rio Madeira. Desenvolvimento sustentável. Trabalho digno e decente. Impactos nas relações laborais.

\begin{abstract}
This scientific article seeks to promote an analysis of the concept of sustainable development and related international standards, in order to promote its understanding as decent and decent work, in order to expose the facts arising from the implementation of the works of the Madeira River Power Plant Complex, to check whether the working relationships provide these projects were competent in their implementation. In this way, it seeks to investigate the impacts experienced in labor relations and non-compliance with existing norms governing these conceptions. This study takes place through the deductive approach method, using comparative, monographic and bibliographic procedure, to connect such ideas and demonstrate that the works carried out did not seek the development of a sustainable social environment by not implementing decent and decent working conditions.
\end{abstract}

Keywords: Power plants on the Madeira River. Sustainable development. Decent and decent work. Impacts on labor relations.

\section{INTRODUÇÃO}

1 Doutor em Direito pela UNESA/RJ (2020). Em Estágio pós-doutoral na Universidad de Salamanca (2021). Mestre em História pela Pontifícia Universidade Católica do Rio Grande do Sul (2015) e Mestre em Direito Internacional - Universidad Autonoma de Asuncion (2009). Graduação em Direito pela Universidade Federal de Goiás (1999). Professor da FARO - Faculdade de Rondônia. Foi professor da FCR - Faculdade Católica de Rondônia. 
A presente pesquisa objetiva realizar uma análise do conceito de desenvolvimento sustentável e a sua compreensão como trabalho decente, para associar tais concepções com as obras de construção das usinas do rio Madeira e como estas impactaram as relações de trabalho em seus parâmetros mais amplos.

Ao investigar as questões de ordem econômica, social e ambiental que se apresentam no contexto da solidariedade intergeracional, a preocupação de diferentes concepções de sustentabilidade e da efetivação dos direitos humanos, sob um contexto da realidade na cidade de Porto Velho, Rondônia e da interrupção do rio Madeira pelas usinas hidrelétricas é o que se problematiza e busca responder.

Os usos desmedidos dos bens naturais para movimentar a roda da produção mundial de bens de consumo acabam por levar a discussões sobre a necessidade de promover modificações do uso dos recursos ambientais, sendo que as mudanças destas realidades necessitam de novos paradigmas de como a natureza deve ser entendida, com o fito de estabelecer outros valores e perspectivas como meio de modificar a geração de riqueza e de trabalho. Nesse sentido, deveria fomentar uma produção que utilize a natureza de forma sustentável e gere riqueza de forma horizontal, combatendo a desigualdade nas relações sociais e promovendo a dignidade para todos os atores sociais envolvidos.

O que se busca é observar uma concepção de Direito sobre o uso dos bens e a disposição da riqueza, para superar uma concepção centrada na acumulação decorrente do extrativismo de matérias primárias na geração de riquezas, de modo que as sociedades envolvidas e a natureza não sofram com a exploração exacerbada e predatória, bem como a promoção do trabalho se dê de modo edificante, decente e se apresente sustentável e equilibrado.

A norma internacional acabou, por uma série de normas, de caráter obrigacional ou não, que acabaram por estabelecer as noções de desenvolvimento sustentável e como tais acepções se apresentam para reger as relações trabalhistas.

Em suma, o presente artigo pretende promover uma análise das relações de trabalho no contexto das obras das usinas do rio Madeira e as suas conexões com as normas internacionais referentes à concepção de desenvolvimento sustentável, dado que faz tal estudo por via do método de abordagem dedutivo, usando do procedimento comparativo, monográfico e bibliográfico para conectar tais ideias e demonstrar que as obras realizadas ao 
não promoverem condições dignas e descentes de trabalho não buscam o desenvolvimento de um ambiente social sustentável.

\section{DA DESCRIÇÃO DAS OBRAS DE CONSTRUÇÃO DAS USINAS DO RIO MADEIRA}

O Brasil possui território vasto e rico em recursos hídricos, principalmente de água doce, é um dos países do continente sul-americano que se propõe a construir represas e complexos hidrelétricos para a produção de energia elétrica, ocupando um lugar de destaque em sua matriz energética, representando $70 \%$ de sua energia produzida no ano de 2018 (MELO; PAULA, 2008). Dessarte, com a necessidade de aumento na produção energética, por conta dos problemas gerados pela crise do Apagão em 2001, quando a energia hidráulica respondia por $84 \%$ do total da oferta de energia elétrica no Brasil, bem como em decorrência de interesses regionais, na efetivação de projetos de infraestrutura junto à IIRSA, eram imperativas medidas para atendessem a crescente demanda energética.

Se a base já era potencialmente hidráulica, a mesma aposta se deu para potencializar este mercado, sendo que "o Complexo Madeira tem sido tratado no setor de geração e transmissão de energia como a 'ponta de lança' do 'avanço da fronteira elétrica' no Brasil e pelo governo como uma obra fundamental para equilibrar a demanda e a oferta de energia elétrica entre 2012 e 2020.” (MONTEIRO, 2011, p. 03).

As usinas planejadas para o Complexo usinas do Rio Madeira foram estabelecidas com o propósito de atender a população local e o Operador Nacional do Sistema (ONS), ante os interesses nacionais de geração de energia para o incremento da sua matriz energética, como também para atender os interesses regionais internacionais de interligação de modais de transporte e comunicações.

E assim se indicou tal complexo para a geração de energia elétrica e infraestrutura regional, definindo-se o Rio Madeira para tal construção, mas não sem gerar uma grande polêmica tanto nacional, quanto internacional pelos graves impactos sociais e ambientais que causariam, não só no território brasileiro, mas também no boliviano (MELO; PAULA, 2008).

$\mathrm{O}$ rio escolhido para o projeto deste Complexo, atendendo ao estabelecido pelos interesses da IIRSA, Segundo AIDA (2009, p. 1-2),

É o mais largo e importante afluente do rio Amazonas em virtude da sua biodiversidade. Esse rio recebe água da Cordilheira dos Andes e contribui com 35\% 
dos sedimentos que fluem na direção do Amazonas. A superfície da bacia hidrográfica do rio Madeira tem quase 125 milhões de hectares, que constituem quase $20 \%$ da área da bacia amazônica. Muitos dos formadores do rio Madeira, como os rios Madre de Dios, Beni e Mamoré, nascem nas zonas andinas da Bolívia e do Peru. Pela riqueza de sedimentos e nutrientes que recebem as águas da região, estima-se que a zona do rio Madeira é uma das áreas mais biologicamente diversas de toda a bacia amazônica e que as regiões do Madre de Dios e Beni têm o nível de biodiversidade mais elevado do planeta.

O projeto do Complexo Hidrelétrico do Rio Madeira importou na construção de duas grandes usinas neste rio: a Hidrelétrica Jirau, com uma potência instalada de até 3.300 MW, e a Hidrelétrica Santo Antônio, de 3.150 MW, para a produção de energia elétrica para o ONS, com o objetivo de substituir uma série de termelétricas consumidoras de combustível fóssil.

Nos estudos realizados pela Leme Engenharia (2005), o rio Madeira em seu perfil longitudinal o qual estabelece um curso que se dirige do planalto para a planície, no seu curso possui como zona de confluência de impacto do Complexo do encontro entre os rios Beni e Mamoré até as proximidades da cidade de Porto Velho, apresenta uma alta declividade e um relevo rico em corredeiras, lajeados e cachoeiras. (MELO; PAULA, 2008)

No trecho entre o distrito de Abunã e a zona urbana de Porto Velho, o rio Madeira percorre cerca de $300 \mathrm{~km}$, apresentando um desnível em torno de 39 metros de altura, mas que não permite condições de navegabilidade em razão das cachoeiras, corredeiras e desníveis no rio que decorrem do afloramento de rochas no seu leito. Dos mais de 18 desníveis diferentes existentes no curso do rio neste trecho, três são de grande importância para este Complexo, sendo elas as cachoeiras de Jirau, Caldeirão do Inferno e de Santo Antônio.

Um rio com um volume elevado de água, que despeja quase $29.000 \mathrm{~m}^{3} / \mathrm{s}$ de vazão média em sua foz (FERREIRA, et al. 1988), sendo o maior afluente do rio Amazonas, contribuindo com $15 \%$ da carga despejada no principal rio da bacia amazônica, sendo o segundo maior sistema de águas claras da Amazônia, situando-se atrás do rio SolimõesAmazonas, com a maior contribuição da carga de sedimentos transportada pelo rio Amazonas. Inclusive esta grande vazão foi um dos motivos determinantes para a realização das obras das duas usinas, já que o relatório descreveu que "as altas vazões de água que o rio Madeira apresenta durante todo o ano possibilita a adoção de uma categoria de turbina (bulbo) para as usinas que operam com baixas quedas; por isso, não exigem grandes reservatórios" (LEME ENGENHARIA, 2005, p. 10)

O rio é de grande importância para a constituição histórica das cidades de Porto Velho, do distrito do Abunã, Guajará-Mirim e Costa Marques, que os utilizaram como transporte e 
fonte de alimentação para as suas populações, apresentando uma grande biodiversidade em seu leito, o que fez do rio Madeira um importante meio para aquelas pessoas viverem, sendo utilizado para a pesca, agricultura, turismo, transporte e até para o garimpo na região.

Sob estas perspectivas é que se estabeleceram os estudos pela Leme Engenharia Ltda. (2005) de aproveitamento hidrelétrico das cachoeiras de Santo Antônio e Jirau, para a construção das duas usinas hidrelétricas, o relatório apresentou a descrição de condicionantes e premissas para a realização das obras. Os estudos sobre esse aproveitamento hidrelétrico mostrou haver desníveis naturais que garantiriam o uso do seu curso para a geração energética, "uma vez que eixos a montante da cachoeira exigem a implantação de longos canais de fuga, com grandes volumes de escavação, de forma a garantir o aproveitamento da queda natural" (MELO; PAULA, 2008, p. 11).

Neste sentido, Fearnside (2015, p. 138) descreveu que estas condições do rio eram propícias à implementação do sistema de geração energética do Complexo de Usinas do Madeira, tendo em vista que:

\begin{abstract}
As barragens de Santo Antônio, de 3.150 MW, e de Jirau, de 3.750 MW, são projetos a fio d'água com turbinas do tipo bulbo, permitindo reservatórios menores do que as barragens tradicionais de armazenamento com turbinas Kaplan ou Francis. Um Estudo de Viabilidade foi elaborado (PCE et al., 2004), simultaneamente com um Relatório de Impacto Ambiental (RIMA) e um Estudo de Impacto Ambiental (EIA) (FURNAS et al., 2005a,b), conhecido, em conjunto, como o "EIA/RIMA".
\end{abstract}

Nesta perspectiva, o projeto foi construído no relatório inicialmente apresentado, com o objetivo de subsidiar inicialmente as bases para as construções das obras das UHE. Assim, as obras avançaram no sentido de promover a construção das barragens com a maior agilidade possível, com o fito de possibilitar a venda livre de energia ${ }^{2}$ no mercado nacional no período anterior ao contratado para a entrega da obra ao governo federal e o início das exigências de venda governamental obrigatória (ZAGALLO; LISBOA, 2011), tudo devidamente indicado e autorizado pela ANEEL.

Assim, promoveram-se a continuidade da construção das obras do Complexo, em ambas as usinas, procedendo todos os atos necessários para a execução dos projetos, na tentativa de cumprir os prazos de entrega e o início da geração de energia de elétrica, de

2 Tal mercado é chamado de Ambiente de Contratação Livre (ACL), quando os agentes e concessionários de energia elétrica podem livremente contratar a venda de demanda energética, sendo regulada pelo Decreto ${ }^{\circ}$ 5.163 , de 30 de julho de 2004, que é definido por este decreto como "o segmento do mercado no qual se realizam as operações de compra e venda de energia elétrica, objeto de contratos bilaterais livremente negociados, conforme regras e procedimentos de comercialização específicos" (BRASIL, 2004). 
forma a proceder à venda antecipada da energia no ACL, como também atender aos ditames de venda estabelecidos nos seus respectivos contratos.

Desta forma, as construções acabaram por causar grandes impactos em toda a região e com as populações que se encontravam no entorno, com o intuito de proceder à geração de energia com a maior brevidade possível, causando grandes transformações no município de Porto Velho e no próprio Estado de Rondônia.

\section{DOS IMPACTOS NAS RELAÇÕES LABORAIS AO TEMPO DAS OBRAS DA CONSTRUÇÃO DAS USINAS DO RIO MADEIRA}

A discussão de impactos laborais permite verificar como se estabeleceu o cumprimento dos direitos sociais e laborais nas obras das usinas do Complexo do rio Madeira, ao se desenvolver suas construções com o cumprimento daquilo que deve se reconhecer como trabalho decente.

No presente ponto, há de se demonstrar que as obras realizadas acabaram por impactar diretamente no exercício do trabalho pelas populações próximas ao rio, como também na supressão dos direitos e garantias trabalhistas para os trabalhadores das usinas do Rio Madeira. As obras focavam na reprodução dos interesses dos grupos ligados às obras, sem o mínimo de preocupação com os reflexos das suas ações com o entorno referentes às relações e os ambientes de trabalho.

Tais ações impactaram diretamente na alteração da relação e da dependência dos ribeirinhos do rio (FEARNSIDE, 2015), como acabaram por diretamente retirar esta população daquele local, sem lhes inserir em outras realidades de trabalho e dependência econômica, mudando as realidades em que estas estavam inseridas.

Sobre o número de trabalhadores tradicionais atingidos, Fearnside (2015, p. 144) apontou que:

Estes números são, sem dúvida, subestimados na área totalizam 2.400 (Ortiz et al., 2007, p. 6). Apenas os membros das cooperativas de pesca sua subsistência. Além de proporcionar emprego, os de pescadores e outros que dependem do rio para a população deslocada é, em grande parte, composta a população que vive ao longo do rio Madeira (...). As atividades de substituição para dar emprego, tais como uma praia artificial e um centro de turismo construídos na antiga cachoeira do Teotônio parecem estar aquém de fornecer um meio de vida viável para essa população. 
Com isso, o período ficou marcado com a necessidade de migração destas pessoas dos seus lugares de moradia para outras localidades, já que as obras impactavam direta ou indiretamente as suas vivendas, como ocorreu com a população do distrito de Mutum-Paraná.

Estas atividades migratórias decorrentes das obras fizeram com que as relações de trabalho desses indivíduos fossem impactadas, tendo em vista que populações ribeirinhas acabaram perdendo condições de exploração do rio (BRASIL DE FATO, 2016), com o aumento do número de pessoas na cidade de Porto Velho, a cidade cresceu desproporcionalmente, sem planejamento e políticas públicas dirigidas ao impasse.

Tais migrações resultaram em desemprego e precarização do trabalho, ligados diretamente ou indiretamente às obras das usinas foram responsáveis no incremento na população em mais 12,5\% entre os anos de 2008 a 2010 (RIBEIRO; MORET, 2014), sendo que no período dos últimos dez anos este crescimento importou em mais de $38 \%$, conforme as estimativas do IBGE para o período. Abordando esta questão, Fonseca, Borges e Lourenço (2016, p. 74), descrevem sobre o aumento da migração, da população local e do desemprego:

Houve um aumento acelerado da população local, devido à grande quantidade de imigrantes atraídos pela possibilidade da oferta de emprego. De fato, cerca de $20 \mathrm{mil}$ empregos foram gerados somente nos canteiros de obras, porém de modo temporário, gerando, assim, um desemprego em massa após a conclusão dos empreendimentos. Além disso, com a chegada dessa nova frente de migração, os equipamentos e serviços urbanos se tornaram insuficientes.

Essa mesma preocupação aparece nas discussões de Ribeiro e Moret, (2014) quando descrevem uma exponencial alteração da realidade local com relação à população e ao mercado de emprego, todos ligados às obras das usinas, as quais geraram grandes impactos em outras áreas do município de Porto Velho. Assim, percebe-se que estas alterações acabaram influenciando diretamente nas relações econômicas, modo de vida da população e nas interações sociais daí decorrentes. Silva (2016) descreve que este clima importou em uma falsa sensação de desenvolvimento, mas que foi logo se desanuviando com a desterritorialização que parte da população do município foi submetida.

Neste sentido Alves e Thomaz Junior (2011, p. 8) descreveram sobre estas mudanças, já que com "a migração intensiva para Rondônia evidencia graves problemas devido à falta de infraestrutura urbana, precário atendimento de saúde e ineficiente política habitacional para atender a crescente demanda".

Essa migração deu-se de diversas formas, sendo realizada diretamente pelas empresas responsáveis pela construção da obra, através de terceiros que atuavam contratando e 
enviando as pessoas para trabalho na região, como também por migração espontânea para a região na busca de trabalho (GERHARDT, 2014), ocasionando o aumento do número de pessoas dispostas ao trabalho.

Desse modo, impactaram-se diretamente os rendimentos que as usinas poderiam gerar com o pagamento de seus funcionários, considerando que o valor recebido pelos trabalhadores acabou se adequando a grande oferta de mão de obra, do modo que formou um grande fluxo de subempregados e precarizados, dado que para trabalhos não-qualificados havia um maior número de trabalhadores disponíveis que permitia a exploração dos trabalhadores com relação às condições e aos próprios ganhos auferidos (ALVES, 2014).

Dessa forma, houve uma série de denúncias de exploração ilegal do trabalho, por empresas terceirizadas pelas usinas do Complexo do rio Madeira, inclusive situações de trabalho em condições análogas à escravidão, Pyl (2009), descreveu que "38 pessoas que construíam vila para desalojados pela Usina Hidrelétrica (UHE) de Jirau foram libertadas de trabalho análogo à escravidão". Tais condições de trabalho foram vistas durante vários períodos das obras realizadas.

Alves; Thomaz Junior (2011, p. 9) ao desenvolverem a discussão a cerca das obras do Complexo de usinas do rio Madeira e as questões relativas ao mercado de trabalho descreveram que:

\footnotetext{
$\mathrm{Na}$ perspectiva dos empreendedores e do Estado parece que os problemas socioambientais e trabalhistas são vistos como empecilhos a tais obras. Todavia, os problemas trabalhistas escamoteados foram revelados pela resistência e revolta de trabalhadores em condições precárias e análogas ao trabalho escravo, situações de exploração e opressão que mesmo com o show erótico de Rita Cadilac (pago pela Camargo Corrêa para aliviar os ânimos dos trabalhadores), não foi suficiente para manter tais relações de exploração "debaixo dos lençóis.
}

Destarte, as discussões levantadas no decorrer dos anos de obras, havendo um número substancial de denúncias e alegações de trabalhadores em condições desumanas, resultaram em intensas atividades de fiscalizações, contudo, não coibiam as situações precárias do ambiente nos quais as obras ocorriam, sendo negligenciados de diversas formas os direitos dos trabalhistas, desde péssimas condições de alojamentos, transportes e refeição até o uso de força e apreensões de documentos (ALVES, 2014).

Ocorreram diversos impasses enfrentados pela classe trabalhadora durante as obras, devido a várias práticas abusivas e por parte de vários empregadores diferentes, tanto ligados diretamente as empresas que promoveram as obras, como pelas empresas indiretamente 
ligadas, mas todos com o objetivo de produzir energia na Amazônia, por via da intensa exploração do trabalho e graves danos causados aos indivíduos e a sociedade.

Essas práticas tinham o objetivo de maximizar o trabalho exercido pelos trabalhadores, gerando economia e ganhos para as empresas relacionadas. Com a exploração dos trabalhadores, esses indivíduos acabavam não tendo a sua direita devidamente atendida, em uma prática reticente e designada ao aumento da produção, sem se importar com a sustentabilidade e direitos relativos ao ambiente de trabalho.

É neste ponto que Alves (2014, p. 399) aponta que as obras das usinas do Complexo do Rio Madeira se pautavam na:

\begin{abstract}
.... precarização no ambiente laboral, inclusive com tratamento aos trabalhadores que paira à condição de Assédio Moral, de agressão, condições irregulares de trabalho, até casos de trabalho análogo à condição de escravo, como já visto. Em suma, mecanismos regressivos, combinados com práticas de reprodução ampliada do capital afinadas aos indicadores tecnológicos e espectrais. Portanto, problemas como a extensão da jornada de trabalho, horas extras não pagas, além da redução de custos com o fornecimento de alimentação de qualidade duvidosa, fornecimento irregular de água potável, condições sanitárias e dos alojamentos reprovadas pelos trabalhadores, marcam o estágio da neobarbárie no canteiro de obras da UHE de Jirau.
\end{abstract}

A precarização do trabalho nas usinas resultou em diversas situações, como: condições de trabalho análogas à escravidão, não concessão efetiva de direitos trabalhistas, promoção de jornadas exaustivas em condições de trabalho degradantes, falta de garantia das devidas condições de saúde para os trabalhadores (GERHARDT, 2014). Dado que, as empresas envolvidas não garantiam a proteção da saúde do trabalhador e de seus direitos, colocando-os em ambientes não propícios ao exercício do trabalho e diante de situações propícias a doenças resultantes dessas condições de trabalho. Os trabalhadores não recebiam treinamentos, equipamentos e informações necessárias para impedir problemas de saúde, por conseguinte acabavam contraindo malária e outras doenças tropicais.

Em decorrência das inúmeras ofensas as normas trabalhistas, saúde e ao ambiente do e trabalho nas obras das usinas e nos locais de trabalho de suas empresas terceirizadas, os órgãos de fiscalização e proteção ao trabalhador promoveram atos na tentativa de minimizar estas ocorrências (ALVES, 2014), embora não contassem com um aparato necessário e condizentes com as reais necessidades de fiscalização desses empreendimentos.

Tais atuações tinham como intuito realizar a fiscalização das condições de trabalho e o cumprimento das normas trabalhistas, ocorrendo de forma periódica ou na apuração de 
denúncia, ou notícias graves existentes, sempre registrando autos de infração pelo não cumprimento das obrigações laborais e relativo à segurança do trabalho, bem como condições contrárias ao bem-estar laboral.

Assim, os números de autos de infração em face destas obras foram extensos e abarcavam diversas empresas ${ }^{3}$, não somente as concessionárias construtoras das obras das usinas, visto que demonstravam optar pela precarização das relações de trabalho e descumprimento das normas existentes que resultavam em grandes impactos nas relações laborais.

Diante de um relatório promovido pelo Ministério do Trabalho e Emprego (MTE), realizado em 2010 na UHE Jirau, foram constatadas irregularidades em que as ofensas a "legislação trabalhista mais comuns foram o excesso de jornada, falta de registro mecânico para controle de jornada, intervalo para descanso irregular, entre outros casos, que estão relacionados nos autos de infração [...]” (BRASIL, SRTE/RO, 2010, p. 13).

No mesmo sentido, Sakamoto (2011) descreveu que somente a UHE Jirau teve até maio de 2011, mais de dois mil, atuações do MTE ocorreram em face de empresas que atuavam na UHE Jirau, sendo que os principais fatos impositivos de tais autos de infração foram o excesso de jornada de trabalho, acidentes com vítimas fatais, horas extras em excesso sem o intervalo mínimo de 11 horas entre as jornadas e a falta de repouso semanal.

Pyl, Santini e Barros (2012) descrevem que houve uma série de registros de infrações pelo descumprimento das normas laborais pela UHE Santo Antônio, como se vê:

Em Santo Antônio, onde, em junho de 2010, o Ministério do Trabalho e Emprego (MTE) registrou 196 infrações trabalhistas no canteiro do empreendimento liderado pelas empresas que compõem o consórcio Santo Antônio Energia, os responsáveis se desdobram para evitar que as reclamações e protestos afetem a imagem do grupo de grandes empresas.

Outra indicação de uma atuação em descumprimento da UHE Santo Antônio foi relatada pela jornalista Ana Aranha (2012), ao apontar que:

Em 2009, quando a usina de Santo Antônio contava com apenas 2.300 funcionários e nenhum acidente fatal, a Superintendência do Trabalho emitiu 49 autos de infração, entre eles, um por 'deixar de instalar proteção coletiva nos locais com risco de queda de trabalhadores ou de projeção de materiais'. Mais de um ano depois, nova fiscalização voltou a encontrar irregularidades, e o número de autos lavrados subiu para 93. Mais uma vez, a falta de proteção para quedas. O MPT moveu uma Ação Civil Pública sobre a reincidência. Nela, faz o alerta: as irregularidades

3 A grande quantidade de empresas envolvidas pelo exercício direto e indireto de funções nas obras das usinas do Complexo do Rio Madeira impede a descrição de um quantitativo preciso de autuações junto ao MTE e a SRTE/RO. 
expõem inúmeros trabalhadores ao 'risco de sua integridade física e a própria vida'. A Santo Antônio Energia foi condenada a pagar R \$ 1 milhão por danos morais coletivos, mas está recorrendo da decisão.

Portanto, ver-se que essas condutas não foram lançadas mão somente por uma empresa, mas realizadas estas atuações de forma ampla e reticente pelos envolvidos na promoção do Complexo de usinas do rio Madeira, em que se criou um ambiente de permissividade e descumprimento das normas do trabalho para a realização das obras em ritmo acelerado em detrimento da segurança, da proteção e do bem-estar laboral.

Tal fato é evidenciado na fala do MPT na Ação Civil Pública promovida em face da UHE Jirau e da União, quando descreveu sobre como estas obras apresentavam:

\begin{abstract}
Fatos que caracterizam graves infrações à legislação trabalhista e à Constituição Federal, na medida em que ofendem a dignidade dos trabalhadores e fazem letra morta dos dispositivos constitucionais que garantem os direitos sociais de milhares de cidadãos contratados para trabalhar na construção da Usina Hidrelétrica Jirau (BRASIL. MPTRO, ACP, 2011, p. 4).
\end{abstract}

Essas práticas eram utilizadas para acelerar as obras com o intuito de gerar energia rapidamente para a venda dessa commoditie junto ao Ambiente de Contratação Livre até a data limite de modo a começar a fornecer energia para o $\mathrm{ONS}^{4}$. As obras ocorreriam sem se preocupar o direito de greve e de manifestação, que por algumas vezes foram impedidos pelos agentes estatais, inclusive com o uso de violência para impedir atos neste sentido, demonstrando a preocupação da rápida entrega de etapas da obra, dando-lhe funcionalidade, deixando de lado a ideia de um ambiente de trabalho de bem-estar e segurança do trabalhador (ALVES, 2014).

Ribeiro e Moret (2014, p. 86) destacaram que o relatório Dhesca de 2011 indicava que as empresas atuavam em suas obras com negligência aos direitos e garantias do trabalhador, como se vê:

O relatório Dhesca (2011), ainda relata que inspeção da Superintendência Regional do Trabalho e Emprego de Rondônia no canteiro de obra da usina hidrelétrica de Santo Antônio em 2010, apontou que a Construtora Norberto Odebrecht estaria atuando com "acentuado grau de negligência". Somente nessa ação foram registrados 267 autos de infração emitidos contra o Consórcio Santo Antônio Energia e/ ou a Construtora Norberto Odebrecht.

4 Neste sentido, Aranha descreve que: "A tensão se intensifica na reta final, quando as empresas mais têm pressa. Santo Antônio ligou as primeiras turbinas em março, nove meses antes do previsto. Jirau está em ritmo acelerado para começar a produção em janeiro. Como parte da energia dessas usinas já foi leiloada em ambiente controlado pelo governo, quanto antes as empresas se anteciparem ao cronograma oficial para início de geração, mais podem vender no mercado livre." (2012) 
É evidente que as obras demonstravam uma política direta e imposta de precarização das condições de execução do trabalho, na promoção de uma superexploração do trabalho, a partir de uma visão de exploração antecipada da obra, não se importando com as consequências laborais descumpridas. Fabre (2015) descreveu que a usina de Jirau foi considerada responsável pela morte de 2 trabalhadores pela inobservância das exigências mínimas das condições para a prestação de serviços com energia elétrica, atuando de forma negligente e não diligente.

Alves (2014) descreveu tal conduta decorreu de uma atuação direcionada pelas empresas na preocupação da rápida geração de excedente energético, na promoção de acumulação de lucros e diminuição de gastos, sem se preocupar com o trabalhador e com as populações no entorno da obra, valendo do pouco aparato público para a fiscalização dessas condutas e a aceitação política em todas as esferas dessas obras, promovendo fortes impactos nas relações de trabalho e nas condições de emprego e exploração econômica do rio e dos demais ambientes, precarizando o trabalho para maximizar os ganhos (GERHARDT, 2014).

\section{DA CONCEPÇÃO DAS NORMAS INTERNACIONAIS SOBRE DESENVOLVIMENTO SUSTENTÁVEL}

O conceito de desenvolvimento sustentável se dá em uma série de normas, principalmente no âmbito internacional, que constituiu a ideia e a disseminou ao longo das últimas décadas. A Assembleia Geral da ONU (2000), através da resolução n. ${ }^{\circ}$ 55/2, de 8 de setembro de 2000, por ocasião da reunião do milênio (Nova Iorque, 6 a 8 de setembro de 2000), adotou uma declaração, expondo princípios e valores jurídicos importantes para ser adotados desta concepção, sendo este:

O principal desafio que se nos depara hoje é conseguir que a globalização venha a ser uma força positiva para todos os povos do mundo, uma vez que, se é certo que a globalização oferece grandes possibilidades, atualmente os seus benefícios, assim como os seus custos, estão distribuídos de forma muito desigual. Reconhecemos que os países em desenvolvimento e os países com economias em transição enfrentam sérias dificuldades para fazer face a este problema fundamental. Assim, consideramos que, só através de esforços amplos e sustentados para criar um futuro partilhado, baseado na nossa condição humana comum, em toda a sua diversidade, pode a globalização ser completamente equitativa e favorecer a inclusão. Estes esforços devem incluir a adoção de políticas e medidas, a nível mundial, que correspondam às necessidades dos países em desenvolvimento e das economias em transição e que sejam formuladas e aplicadas com a sua participação efetiva. 
Este debate já vinha ganhando força em escala global desde a década de 1970, nos debates jurídicos e da própria discussão de tratados e normas internacionais de soft law, para estabelecer a inclusão das discussões de sustentabilidade, promoção da igualdade e da dignidade nas relações existentes, entre outros aspectos jurídicos que apresentam uma nova percepção de como o ser humano passa a se utilizar dos espaços.

Primeiramente um exemplo dessa categoria de normatização no âmbito internacional que trazia esta discussão foi a Declaração de Estocolmo (1972), emitida como documento representativo das ideias discutidas na Conferência das Nações Unidas sobre o Meio Ambiente Humano, a qual buscou a mudança da atuação do homem com relação ao meio ambiente na totalidade, para se ver este bem como é descrito no seu item 1, "essenciais para o bem-estar do homem e para o gozo dos direitos humanos fundamentais, inclusive o direito à vida mesma."

Posteriormente, a Organização das Nações Unidas (ONU) realizou a Primeira Conferência das Nações Unidas sobre Assentamentos Humanos e Desenvolvimento Urbano Sustentável (Habitat I), realizada em Vancouver no Canadá, em 1976, que acabou por criar o Programa de Assentamentos Humanos das Nações Unidas (ONU-Habitat), que consiste no programa da ONU para o trato dos temas relativos aos assentamentos humanos e o desenvolvimento urbano sustentável. Sendo assim, as discussões sobre espaço, cidade e meio ambiente passam a ocupar a centralidade dos debates da agenda internacional, com a necessidade de uma nova realidade jurídica a reger estes campos, levando a inserção destes temas na agenda dos Estados para a construção de caminhos para a sua recepção nos seus respectivos ordenamentos.

Com isso, houve uma nova compreensão de Estado, que não é pautado nos seus próprios interesses, mas na promoção dos fundamentos e objetivos que a ordem constitucional acabou por impor, de forma que o Estado brasileiro deve se pautar na promoção da dignidade a pessoa humana, um de seus fundamentos, bem como atuar para promover (BRASIL, 1988) a "construção de uma sociedade livre, justa e solidária; o desenvolvimento nacional; a erradicação da pobreza e da marginalização e a redução das desigualdades sociais, regionais e a promoção do bem-estar de todos, excluída qualquer forma de discriminação”.

Então, tem-se que o ordenamento jurídico brasileiro acabou por tomar um novo destino, com a designação de elementos normativos constitucionais que importassem na 
necessidade do Estado atuar para promover aos cidadãos meios para participar dos espaços públicos, ter uma vida digna e de garantia dos seus direitos fundamentais estabelecidos no corpo da Constituição e em tratados internacionais de Direitos humanos.

Desse modo, que a ONU-Habitat promoveu a sua II Conferência das Nações Unidas sobre Assentamentos Humanos e Desenvolvimento Urbano Sustentável (Habitat II), realizada em Istambul, Turquia, em 1996, com o intuito de apresentar metas universais para garantir o direito a moradia e abrigo adequado para todas as cidades e seus habitantes, mas também de relações sustentáveis, inclusive de trabalho, de forma que os indivíduos possam alcançar os direitos expressos na Carta da ONU e em seus tratados sobre Direitos humanos.

Na Declaração de Istambul sobre assentamentos humanos, de 1996, em seu item 15, expressa a necessidade de mudança na relação entre os indivíduos com relação aos desafios para o século XXI, descrevendo a necessidade dos Estados promoverem políticas para uma nova visão de assentamentos e de combate a pobreza, ao "construirmos juntos um mundo onde todos possam viver em uma casa segura, com a promessa de uma vida decente, com dignidade, boa saúde, segurança, felicidade e esperança." (ONU, 1996).

Estes são exemplos claros de normas internacionais que tratam diretamente sobre a questão do direito a sustentabilidade, embora uma série de outras acabam por tocar tangencialmente nestas discussões, entre elas: a Agenda 2030 para o Desenvolvimento Sustentável, incluindo os Objetivos de Desenvolvimento Sustentável, a Agenda de Ação de Adis Abeba da Terceira Conferência Internacional sobre o Financiamento para o Desenvolvimento, o Acordo de Paris no âmbito da Convenção Quadro das Nações Unidas sobre Mudança do Clima (UNFCCC), o Marco de Sendai para a Redução do Risco de Desastres 2015-2030, o Plano de Ação de Viena para os Países em Desenvolvimento Sem Litoral para a Década de 2014-2024, o Roteiro das Modalidades Aceleradas de Ação dos Pequenos Estados Insulares em Desenvolvimento (SAMOA) e o Plano de Ação de Istambul para os Países Menos Desenvolvidos para a Década de 2011-2020, como também o compromisso adotado na Declaração do Rio sobre Meio Ambiente e Desenvolvimento, a Cúpula Mundial sobre o Desenvolvimento Sustentável, a Cúpula Mundial sobre o Desenvolvimento Social (Declaração de Copenhague), o Programa de Ação da Conferência Internacional sobre População e Desenvolvimento (CIPD), a Plataforma de Ação de Pequim, a Conferência das Nações Unidas sobre Desenvolvimento Sustentável (Rio+20), e os 
desdobramentos dessas conferências, que abordam a questão do desenvolvimento sustentável e a necessidade da constituição de relações de trabalho sustentáveis e não exploratórias.

A compreensão de sustentabilidade que o Direito internacional proporciona uma forma de produção que se apresentou a partir de uma coesão social, de forma que se buscava o desenvolvimento de todos no processo, respeitando-se as regras existentes e estabelecendo relações equilibradas, o que se aplica a todas as formas de relação, inclusive as relações de trabalho.

Scodro; Martins (2017, p. 191) descreve a sustentabilidade como uma compreensão que se constitui como:

um dever fundamental, que, como tal, não pode ser visto como um princípio abstrato ou passível de adiamento. Nesse sentido, deve ser aplicado desde já a fim de promover o bem-estar físico, psíquico e espiritual dos indivíduos, a partir da promoção de um desenvolvimento limpo e sadio pelo equilíbrio e pela dialeticidade entre as dimensões social, ética, ambiental, econômica e jurídico-política.

Tal compreensão decorre da própria noção de dignidade da pessoa humana, importando em uma sustentabilidade que se apresente como um dever fundamental pautável de desenvolvimento limpo, sadio e equilibrado, em todas as dimensões que se possam imaginar de relações, inclusive nas dimensões sociais as quais as interseções laborais estão inseridas.

Tanto é assim que o Relatório Brundtland, ao falar sobre o "Nosso futuro comum", indicou que o desenvolvimento sustentável deve satisfazer as necessidades de todos, a partir de um entendimento de progresso econômico e social, para atender as necessidades com igualdade e equilíbrio. Isso também foi expresso na Agenda 21, que acabou por inserir no seu capítulo 3 a necessidade de se combater a pobreza e no seu capítulo 15 ao se descrever a necessidade de fortalecimento do papel dos trabalhadores e de seus sindicatos. Tais normativas acabaram se preocupando com estabelecer privados de ordem ético-jurídica que os sistemas de produção devem assegurar a qualidade de vida, a satisfação das demandas das demais gerações e a constituição de oportunidades para todos, incluso com relação ao acesso ao trabalho digno.

Sobre o tema, a Organização Internacional do Trabalho (2008, p. 2) descreve a noção de trabalho decente:

O trabalho decente satisfaz as aspirações das pessoas em suas vidas profissionais por oportunidades e renda; direitos, participação e reconhecimento; estabilidade familiar e desenvolvimento pessoal; justiça e igualdade de gênero. Em última análise, essas diferentes dimensões do trabalho decente constituem a base para que a 
paz seja efetivamente estabelecida em comunidades e na sociedade. $\mathrm{O}$ trabalho decente é essencial nos esforços voltados à redução da pobreza e é um meio de se alcançar um desenvolvimento equitativo e inclusivo.

Destarte, só uma concepção de desenvolvimento sustentável em que o desenvolvimento vivenciado importe na implementação do trabalho decente nas relações de produção, integrando-se a noção de crescimento com progresso social e combate à pobreza em sua acepção, na observância dos marcos normativos internacionais sobre a questão sustentabilidade, que deve respeitar no "exercício da atividade laborativa em condições de igualdade de gênero com condições de liberdade, equidade e segurança, com salários satisfatórios e respeito aos direitos trabalhistas, consistindo em um direito humano" (SCODRO; MARTINS, 2017, p. 210). O Estado tem um papel importante nas ações que visam regular a apropriação da natureza pelo capital, devendo garantir as condições necessárias para que as obras se dessem e usem a natureza, mas a partir do cumprimento de condições de sustentabilidade e precaução nos projetos.

\section{DA FALTA DE OBSERVÂNCIA DAS NORMAS SOBRE DESENVOLVIMENTO SUSTENTÁVEL AO PROMOVER IMPACTOS NAS RELAÇÕES LABORAIS/SOCIAIS EM TAIS OBRAS}

Ao conectar as ideias aqui tratadas, há de se ver que as relações de trabalho devem respeitar as compreensões de desenvolvimento sustentável no estabelecido das atividades empreendidas, tanto no âmbito de atuação pública, como privada. Sendo assim, ao se tratar de sustentabilidade, não estamos tratando somente sobre questões correlatas ao meio ambiente e a sua proteção, mas a necessidade de estabelecer projetos que respeitem as regras estabelecidas e promovam o progresso social e ambiental.

Costa (2016, p. 98) ao descrever esta situação, apresente que:

A construção de empreendimentos de grande porte na região amazônica requer um conhecimento prévio de todos os programas e projetos existentes na região, especialmente aqueles que buscam a promoção do desenvolvimento sustentável, devendo ser observadas as suas premissas sob pena dos empreendimentos se alicerçarem em uma ótica puramente econômica (...).

Nesta perspectiva que se constrói todo o Complexo de usinas, para a geração energética a partir de um produto de baixo custo, que permita a sua renovação constante, mas sem as precauções necessárias para o desenvolvimento sustentável. 
O desenvolvimento sustentável, não é simplesmente compreendido com o uso consciente do meio ambiente, mas da correta aplicação das normas nas regências das relações humanas existentes, deve ser sempre buscado, de forma que as relações estabelecidas importem no cumprimento das boas práticas e normas de regência das relações laborais.

Portanto, deriva de uma conjugação de preocupações do cumprimento das normas existentes, para permitir a constituição de ambientes que sejam limpos, de qualidade e sadios, mas que também importem em garantir a efetivação dos direitos sociais, inclusive pela promoção do trabalho decente.

Isto é, há de se propagar a ideia de busca pela proteção à natureza e do meio ambiente, com o uso consciente e necessário dos recursos naturais, mas que também importe em um ambiente social e humano de diminuição das desigualdades, de promoção das dignidades e de liberdades plenas para todos. Esta categoria de desenvolvimento deve garantir a vida, o equilíbrio, da biodiversidade e dos seres que habitam em um ambiente, com respeito as práticas e tradições, ao instrumentalizar uma convivência social pautada na pluralidade e dignidade humana em harmonia com a natureza.

Por isso, devem se dar tais atividades, mas quando falamos nas obras da construção das usinas do Complexo do rio Madeira, estas não foram as realidades enfrentadas, já que as obras importaram em diversas categorias de relações trabalhistas, mas que não promoveram uma concepção de sustentabilidade laboral, ao não garantir condições para o exercício do trabalho com dignidade e justeza.

Alves (2014, p. 255), ao tratar as questões relativas às obras das usinas do rio Madeira, bem como o ambiente social constituído em decorrência destes projetos, aponta para o descumprimento de uma perspectiva de sustentabilidade, ao indagar:

\footnotetext{
Questiona-se que desenvolvimento sustentável é este desestruturador da vida, de territórios de populações ribeirinhas, extrativistas, camponesas, indígenas, de trabalhadores nos canteiros de obras, que desarticula espaços de vida em detrimento de espaços de acumulação, que gera graves problemas ambientais, socioeconômicos, de segurança e saúde pública, tanto no campo como na cidade?
}

Ao analisar os espaços produzidos no entorno dos projetos e as relações estabelecidas, as ações empreendidas não importaram na diminuição da desigualdade e a resolução de problemas sociais já existentes, mas no crescimento de problemas sociais e do bom ambiente de trabalho, já que as ações implementadas acabaram por fomentar as exclusões e o empobrecimento da população. 
A energia produzida se apropriou dos recursos naturais, mas não garantiu a distribuição de riqueza e o combate à desigualdade, importando na perpetuação de políticas de ineficiência e inefetividade na implementação de direitos sociais.

Saule Junior (2006, p. 71) descreveu que estas obras não se apresentaram de forma sustentável, necessária uma série de compensações para minimizar os impactos das obras, já que:

(...) é evidente que os impactos causados pelos empreendimentos não se limitam à esfera ambiental: eles também atingem às comunidades e populações que habitam nas proximidades do empreendimento. Isto significa que a execução de medidas compensatórias ambientais não garante que o empreendimento atenda ao desenvolvimento sustentável.

As obras deveriam importar na melhoria de vida dos indivíduos, a aptidão das pessoas para escolherem suas atividades, como descrito por Scodro e Martins (2017 p. 202), estas deveriam impor "forma que melhor lhes aprouver, e a possibilidade de usufruir das liberdades sociais, econômicas e políticas reiteram a condição de agente do trabalhador".

As obras deveriam implementar a melhoria das condições de trabalho decente e da proteção ambiental laboral, ao impor liberdades, equidades e segurança nas relações, mas acabaram por assim não se dar.

Mas isso já era esperado, tanto que em estudo contratado previamente pelo Município de Porto Velho abordando a questão das usinas, constatou-se que:

\footnotetext{
As leis orçamentárias do Município de Porto Velho - Plano Plurianual 2006-2009, Lei de Diretrizes Orçamentárias e Lei Orçamentária Anual de 2006 - não preveem ações que deem suporte a implantação do empreendimento das hidrelétricas de Santo Antônio e Jirau em Porto Velho. Não estão previstas e orçadas ações e políticas que garantam a minimização dos impactos e garantia do desenvolvimento sustentável da cidade de Porto Velho.” (SAULE JÚNIOR, 2006, p. 42)
}

Nota-se que com a implementação das obras formou um ambiente que não visava uma ampla prosperidade socioeconômica, para alcançar a todos na formação de um projeto público de desenvolvimento social e ambiental equilibrado e sustentável. Na verdade, viu-se a nãoefetivação dos direitos sociais e o enfraquecimento de medidas do combate à desigualdade e que não prezaram pela criação de condições de trabalho decentes e dignas.

\section{CONSIDERAÇÕES FINAIS:}


$\mathrm{Na}$ presente pesquisa, é importante compreender que as obras foram realizadas com o intuito de geração de riqueza energética para o país, em um universo de oportunidades que exsurgiriam não somente para utilização da energia gerada a um preço acessível, mas também para permitir o desenvolvimento e o combate das desigualdades nas sociedades afetadas.

Ademais, deveriam se suplantar as condições anteriormente existentes nos espaços sociais com relação à pobreza e a implementação de condições de trabalho decentes e dignas, porém o que se viu foi o aprofundamento das condições de acumulação e desigualdade, já que estas importaram na imposição dos interesses das classes dominantes e submetendo as classes trabalhadoras a situações de exploração, descumprimento das normas laborais regentes. Dessa forma, perpetuando as conjunturas de pobreza e renegando a uma parte da população os direitos humanos e fundamentais estabelecidos.

Outrossim, nota-se que as obras deveriam proporcionar condições que visassem a melhoria da qualidade de vida e do uso da natureza, no entanto, perpetuaram as situações anteriormente vivenciadas de exclusão, indignidade e injustiça para boa parte da população, já que acabou por constituir um ambiente de insustentabilidade social, em que as riquezas geradas não alcançam a população de forma ampla e geral, mantendo as realidades anteriormente existentes.

Por fim, as obras a geraram energia de base expropriativa, degradante e de insustentável uso da natureza, como também produzindo espaços de exploração e improbidade nas relações laborais existentes em tais obras e no seu entorno, não resultando em um meio ambiente de trabalho emancipatório e dignificante, como deveria se dar no desenvolvimento nestas categorias de políticas.

\section{REFERÊNCIAS}

AIDA. Complexo Hidrelétrico do Rio Madeira. In: AIDA. Informe Grandes Represas na América, Pior o Remédio que a Doença? [s.1]. Asociación Interamericana para la Defensa del Ambiente, 2009. p. 01-13. Disponível em: http://bit.do/eZ34n. Acesso em: jun. 2019.

ALVES, José. As revoltas dos trabalhadores em Jirau (RO): degradação do trabalho represada na produção de energia elétrica na Amazônia. 2014. 671 f. Tese (Doutorado em Geografia) Faculdade de Ciências e Tecnologia, Universidade Estadual Paulista, Presidente Prudente, 2014.

ALVES, José; THOMAZ JUNIOR, Antônio. A degradação do trabalho no "Complexo Hidrelétrico Madeira": Apontamento sobre a UHE Jirau. Revista Pegada Online, Presidente Prudente, vol. 12, n. 2, p. 1 - 19, dez. 2011. 
ARANHA, Ana. RIO MADEIRA: Os trabalhadores que pararam o progresso, Pública, 2012. Disponível em: http://bit.do/foXoE. Acesso jan 2021.

BRASIL DE FATO. Vila construída pela Usina de Jirau desconsidera cultura local e vira cidade fantasma, 2016. Disponível em: http://bit.do/ffPsw. Acesso em31 out 2019.

BRASIL. Ministério Público do Trabalho. Procuradoria Regional do Trabalho da $14^{a}$ Região. Ação Civil Pública. N. 00268-2011-003-14-005, da $3^{\text {a }}$ Vara do Trabalho de Porto Velho. Porto Velho, Banca 4, Réu Construções e Comércio Camargo Corrêa S/A. Autuação: 18/03/2011. 3 v. e Anexo.

Decreto $n^{\circ} 5.163$, de 30 de julho de 2004, que regula a comercialização de energia elétrica. 2004b. Disponível em: shorturl.at/vxAOY. Acesso jan 2021.

Ministério do Trabalho e Emprego. SRTE/RO. Relatório de fiscalização. UHE Jirau -Porto Velho.V. 1 e 2. (Programa de Auditoria Especiais em obras de infraestrutura). 2010.

FABRE, Ana. Falta de segurança pode ter causado mortes em usina de RO, diz Ministério. G1, 2015. Disponível em: http://g1.globo.com/ro/rondonia/noticia/2015/06/falta-deseguranca-pode-ter-causado-mortes-em-usina-de-ro-diz-ministerio.html. Acesso jan 2021.

FEARNSIDE, Philip M. Impactos das barragens do Rio Madeira: Lições não aprendidas para o desenvolvimento hidrelétrico na Amazônia. In: FEARNSIDE, Philip M. Hidrelétricas na Amazônia: Impactos Ambientais e Sociais na Tomada de Decisões sobre Grandes Obras. Manaus: Editora do Instituto Nacional de Pesquisas da Amazônia (INPA), 2015. p. 137-151, Vol. 1.

FONSECA, Rafael Oliveira; BORGES, Luciana Rica Mourão; LOURENÇO, Suzana Cristina. Estado, Mercado e Meio Ambiente: Uma analise sobre a implantação de Usinas Hidrelétricas na Amazônia brasileira. Geofronter, Campo Grande, v. 2, n. 1, p. 59-89, jan./jun., 2016.

GERHARDT, Ana Flora Camargo. Impactos na saúde dos trabalhadores das Usinas Hidrelétricas de Santo Antônio e Jirau do Rio Madeira - sob a ótica da Vigilância em Saúde do Trabalhador. 2014. 142 f. Dissertação (Mestrado), Escola Nacional de Saúde Pública Sérgio Arouca, Rio de Janeiro, 2014.

LEME ENGENHARIA. Relatório de Impacto Ambiental: Usinas Hidrelétricas de Santo Antônio e Jirau. [s.1], 2005. Disponível em:www.ibama.gov.br/licenciamento/index.php. Acesso mar 2021.

MELO, João de Jesus Silva. PAULA, Elder Andrade de. As "Hidrelétricas no Rio Madeira no Contexto da Integração Regional Sul-Americana". In IV Encontro da Associação Nacional de Pesquisa e Pós-Graduação em Ambiente e Sociedade - ENANPPAS. Brasília, 2008.

Disponível em <shorturl.at/qGKY0>. Acesso em mai/2018.

MONTEIRO, Telma. Energias hidrelétricas: as Hidrelétricas do Madeira: as lições não aprendidas que se repetem em Belo Monte. São Paulo: Observatório de Investimentos na Amazônia, 2011.

OIT. Empregos verdes:trabalho decente em um mundo sustentável, com baixas emissões de carbono. Brasília: Organização Internacional do Trabalho, 2008.

PYL, Bianca. Trabalho escravo é encontrado em obra ligada à usina do Madeira, Repórter Brasil, 2009. Disponível em: http://bit.do/fw7as. Acesso jan 2021. 
PYL, Bianca; SANTINI, Daniel; BARROS, Carlos Juliano. Mesmo com acordo, greves e violações persistem em obras, Repórter Brasil, 2012. Disponível em: http://bit.do/fhTSC. Acesso mar 2021.

RIBEIRO, Aureni M.; MORET, Artur de S.. A Construção da Hidrelétrica de Santo Antonio e os impactos na sociedade e no Ambiente. Interfaces Científicas - Humanas e Sociais, Aracaju, v. 2, n. 3, p. 81-92, jun., 2014.

SAKAMOTO, Leonardo. Baseado em relatórios da SRTE/RO, MPT entra com ação contra construtoras da Usina de Jirau. Blog do Sakamoto, 2011. Disponível em: http://bit.do/foWXa. Acesso em jan 2021.

SAULE JUNIOR, Nelson; CARDOSO, Patricia de Menezes; MOURAD, Laila. Parecer sobre o papel do município de Porto Velho frente aos impactos urbanos e o estudo de impacto ambiental do projeto das usinas hidrelétricas do Rio Madeira. Sao Paulo: Instituto Polis, jun. 2006.

SCODRO, Catharina L.; MARTINS, Juliane C. O desenvolvimento sustentável e o trabalho decente: uma análise a partir da 'condição de agente' do indivíduo e da redução a condição análoga a escravo. Revista de Estudos Jurídicos Unesp, a. 21, n. 33, 2017, p. 187-210.

SILVA, Girlany Valeria Lima da. Hidrelétrica de Santo Antônio no Rio Madeira/Rondônia e a (des)territorialização da Comunidade de Teotônio: E possível uma (re)territorialização? 2016. 106 f. Dissertação (Mestrado em Geografia) - Núcleo de Ciências Exatas e da Terra, Fundação Universidade Federal de Rondônia, Porto Velho, 2016.

ZAGALLO, Jose Guilherme Carvalho; LISBOA, Marijane Vieira. Relatório Preliminar de Missão de Monitoramento. Violações de direitos humanos nas hidrelétricas do Rio Madeira: relatório preliminar de missão de monitoramento. Curitiba, abr. 2011. Plataforma DHESCA. 